\title{
Utility Of E-learning in Community Medicine: A Mixed Methods Assessment Among Indian Medical Students
}

\author{
Pracheth Raghuveer, Abhay Subhashrao Nirgude
}

Pracheth Raghuveer, Abhay Subhashrao Nirgude

Department of Community Medicine, Yenepoya Medical College, Yenepoya University, Mangaluru, Karnataka, INDIA.

\section{Correspondence}

Pracheth Raghuveer, Department of Community Medicine, Yenepoya Medical College, Yenepoya University, Deralakatte, Mangauru-575018, Karnataka, INDIA.

Phone no: +0824 2453769;

Mobile:09743289207

Email: prach1986@gmail.com

\section{History}

- Submission Date: 17-02-16;

- Review completed: 15-05-16;

- Accepted Date: 17-06-16.

\section{DOI : 10.5530/ijmedph.2016.2.7}

Article Available online

http://www.ijmedph.org/v6/i2

\section{Copyright}

(C) 2016 Phcog.Net. This is an open-access article distributed under the terms of the Creative Commons Attribution 4.0 International license.

\begin{abstract}
Introduction: We conducted this study to assess the utility of e-learning as a teaching and learning method in Community Medicine using quantitative and qualitative methods.

Methods: We carried out a cross sectional study to fulfill the study objectives for a period of three months. The study participants were undergraduate students of a Private Medical College, who were exposed to e-learning conducted by the Department of Community Medicine. Thus, we invited a total of 437 students to take part in this study. A self-administered, pre-tested, pre-designed and validated questionnaire was used for quantitative assessment. Qualitative assessment was conducted by a Force Field Analysis (FFA) on a subset of the study population.

Results: A total of 323 medical students participated in the study, of which $82.35 \%$ believed that they were confident overall in using a computer, $78.33 \%$ considered themselves as having good computer skills. Majority utilized e-learning (76.16\%) while $81.74 \%$ reported that they are confident in use of e-learning. Demonstration videos if uploaded would be useful according to $76.78 \%$ of the study participants. Most of the study participants agreed that e-learning is useful (62.29\%). Through FFA, we were able to identify certain key driving forces associated with e-learning use. Moreover, factors like lack of user friendliness and a slow network were identified as restraining forces.

Conclusion: Majority were of the opinion that e-learning is an effective learning tool. However, successful execution of an e-learning programme can be ensured if the barriers are overcome and orientation programmes are conducted.
\end{abstract}

Key words: E-learning, Utility, Attitudes, Force Field Analysis.

\section{INTRODUCTION}

Undergraduate medical education has witnessed a recent upsurge in the usage of computers and computer-assisted instructions to make learning effective. ${ }^{1}$ E-learning is one such approach that is gaining prominence in medical education and employs modern technologies such as web based education methods, podcasting, social networking software, internet video conferencing or computer-assisted instruction. ${ }^{2}$ Distance learning and computer assisted instruction are the two varieties of e-learning commonly practiced to deliver education. Distance learning provides instructions to learners who are at a distant location through the application of information technologies while computer assisted instruction delivers multimedia packages for learning with the help of computers. $^{3}$ Of late, Medical Colleges have invested considerably in the development of e-learning to provide an efficient and economical learning environment. ${ }^{4}$ Besides, studies conducted in the past by a few researchers have touched this topic of e-learning among medical students. ${ }^{1-3}$
In a study carried out by Mehra et al among medical students of an Indian University, 76\% of the students displayed positive attitudes towards e-learning, while $82 \%$ implied that e-learning will be useful to them. Moreover, more than half of the medical students were willing to embrace e-learning as a learning tool. ${ }^{5} \mathrm{How}$ ever, research has also suggested that some students may lack the necessary skills to use e-learning effectively. The medical students' perceptions regarding e-learning is another cause for concern. ${ }^{6}$ Thus, an assessment of the attitudes and experiences of the undergraduate medical students towards e-learning is much needed. Furthermore, such an assessment may help to identify and address the difficulties encountered in the implementation of an e-learning programme in a Medical College setting. ${ }^{4}$ A thorough understanding of the hindering and motivating factors with respect to e-learning is critical in effective and efficient use of e-learning as a teaching, learning and assessment tool. This may be accomplished by adopting a mixed method approach for assessment which includes both qualitative as well as quantitative methods. The addition of a qualitative component to the study design, may help to gain valuable insights regarding the issue from a medical students' perspective.? 
With this milieu, we undertook this study to assess the utility of the e-learning process as a teaching and learning method in Community Medicine among Undergraduate students of a Medical College in India and to explore the driving and restraining forces influencing the use of e-learning among the study participants.

\section{MATERIALS AND METHODS}

We adopted a cross-sectional study design using a mixed methods approach involving both quantitative and qualitative elements to fulfill the study objectives. The study was conducted for a period of three months from November, 2014 to January, 2015, in a Private Medical College of South India, recognized by the Medical Council of India. The Medical College has a total of 900 medical undergraduate students at present and has been set up with the primary objective of providing quality medical education through various Departments which work collectively to realize this objective.

The Department of Community Medicine is one such unit that has been established to provide comprehensive, community oriented training to the medical students and has implemented e-learning as a method for teaching, learning and assessment on a consistent basis, from the year 2013, in addition to the conventional methods of teaching, learning and assessment like lectures, practical classes, theory and viva-voce examinations. Thus, e-learning is one of the platforms made available to all the students for facilitation of learning. The mode of e-learning practiced by the Department is computer-assisted instruction. The e-learning database maintained by the Department contains various resources like PowerPoint Presentations of lectures, images and illustrations, a few videos relevant to Community Medicine and questions for online assessments and assignments. At the end of every lecture, the faculty upload the PowerPoint Presentation and lecture notes to the e-learning portal. Moreover, online forums to facilitate quality subject-related discussion among the students are also set-up. Furthermore, feedback is obtained from the students on a periodic basis.

This study was carried out in 2 phases, phase 1, a questionnaire-based quantitative assessment and phase 2, a qualitative assessment (Figure 1).

\section{Phase 1: Questionnaire-based quantitative assessment}

The undergraduate medical students who have participated in the e-learning activities conducted by the teaching faculty of Department of Community Medicine and agreed to give consent for the study on a voluntary basis were invited to participate in this study, while those not exposed to e-learning activities conducted by the Department of Community Medicine and those not giving consent were excluded. Thus, a total of 437 undergraduate medical students were invited to participate in the study, of which 149 were students of Third Year, Bachelor of Medicine Bachelor of Surgery (MBBS)-Part I while 288 were studying in the Second Year, MBBS. A total of 114 (26.09\%) were considered as non-respondents which included those who could not be reached despite two visits to the class and refused to give consent for the study.

We collected the data by using a self-administered, pre-designed and pre-tested questionnaire. Informed written consent was obtained from all the study participants. The study participants were enquired about the pattern of computer and internet usage, self-perceived computer skills, self-perceived proficiency regarding e-learning use, perceived usefulness of various e-learning resources as teaching, learning and assessment methods. Furthermore, the attitudes of the study participants about e-learning were also assessed. The questionnaire was filled up by the participants under our observation.

\section{Statistical analysis}

The data was analyzed by Statistical Package for Social Sciences (SPSS), Version 17.0. Chicago, SPSS Inc. Descriptive statistics like percentages and proportions were applied for the analysis of categorical variables.

\section{Phase 2: Qualitative assessment}

Qualitative assessment was carried out by Force Field Analysis (FFA), a technique developed by Kurt Lewin, employed to identify and analyze the forces affecting a problem situation, so as to bring about a change. ${ }^{8}$ FFA is an important tool which facilitates the diagnosis of situations and controlling changes within organizations and communities. Kurt Lewin assumed that in any situation there are both driving and restraining forces that influence any change that may occur. Driving forces are forces that influence a situation, pushing in a particular direction while restraining forces are forces that act to restrain or decrease the driving forces. Equilibrium is the status quo or the present level of productivity, and can be disrupted or fortified by changes in the relationship between the driving and the restraining forces. Equilibrium is reached when the sum of the driving forces equals the sum of the restraining forces. Furthermore, Kurt Lewin proposed that whenever driving forces are stronger than restraining forces, the status quo or equilibrium will change. Successful change is achieved by either strengthening the driving forces or weakening the restraining forces. Thus FFA is a useful technique for looking at all the forces for and against a plan and helps to identify changes that can be undertaken to improve it. ${ }^{9}$

FFA was conducted on a group of randomly selected 16 students who participated in Phase 1 of the study. To ensure equal representation from both the Third Year MBBS and Second Year MBBS students, 8 students were selected from each class. Thus, 2 sessions of FFA were held on groups of 8 participants each. The purpose and nature of the assessment was explained to the study participants. Written informed consent was obtained. The participants were made comfortable and an atmosphere to freely interact was created. Later, they were made to define the present situation and problem as well as the major goal or the desired change. The group was then asked to depict the present situation diagrammatically and state a goal on a sheet of paper, after which they were told to enlist the forces that motivated them to use e-learning (driving forces) and the forces that hindered the use of e-learning (restraining forces). Further, they were instructed to select any one of the driving forces they could strengthen or one of the restraining forces, which could be reduced or weaken. Taking this force as the new situation, they then identified a goal in order to work with this force. After a brainstorming exercise, the participants enlisted the driving and restraining forces related to their new sub-goal. The driving and restraining forces were then scored according to their magnitude, ranging from one (weak) to five (strong). This process was repeated twice, to facilitate a better analysis of the influencing factors.

\section{Ethical considerations}

The study was approved by the Institutional Ethics Committee. Detailed information pertaining to the nature, objectives of the study and test procedures was provided to the study participants and written informed consent was obtained. Anonymity of the study participants was ensured and utmost confidentiality of the information collected was maintained.

\section{RESULTS}

Our study yielded a response rate of $73.91 \%$, as 91 of the 437 study participants were absent on the day of assessment and could not be reached 
despite two visits to the respective class, while 23 students refused to participate in the study. Thus, a total of 323 undergraduate medical students participated in the study, of which 164 (50.77\%) were males and 159 (49.23\%) were females. The mean age of the study participants was found to be $20.24 \pm 2.58$ years, with the majority (61.30\%) aged $19-20$ years. Almost all the study participants owned a personal computer/laptop $(99.07 \%)$ and $98.76 \%$ had access to the Internet. When the duration of internet use per day was assessed, $63.77 \%$ reported the use of internet several times a day. A high proportion $(66.87 \%)$ of the study participants spent $<1 \mathrm{hr}$ online carrying out academic activities and $37.77 \%$ spent $<1$ hr online on leisure activities (Table 1).

A high percentage (82.35\%) stated that they were confident overall in using a computer. We observed that $78.33 \%$ believed that they possessed good computer skills, $76.16 \%$ affirmed that they were confident in using Microsoft Word, 78.64\% stated that they were well-versed in preparing PowerPoint presentations and $88.84 \%$ were confident in browsing the internet

(Table 2).

It is apparent from Table 3 that a greater number of study participants accessed e-learning (76.16\%). A wide majority (81.74\%) reported that they are self-proficient in using e-learning. A mere $17.65 \%$ accessed e-learning once a day and $34.98 \%$ accessed e-learning few times a week. When the usefulness of different e-learning activities were assessed, $67.80 \%$ found power-point presentations and descriptive texts pertaining to the lecture topics taught, useful. A sizable number (76.78\%) found videos related to the topics taught to be useful, $65.32 \%$ considered discussion forums to be engaging and $72.45 \%$ reported that online quiz are useful. Majority (76.78\%) considered demonstration videos to be helpful. When the study participants were asked regarding their preferred e-learning resource, $31.58 \%$ preferred images and video demonstrations (Table 4).

Most of the study participants agreed that e-learning is useful $(62.29 \%)$. More than half (52.63\%) reported that e-learning improves the teaching standard. However, only a small number $(34.36 \%)$ believed that e-learning is equivalent to traditional teaching (Table 5).

FFA was conducted to systematically analyze the factors for and against e-learning. Through the FFA, the study group was able to enlist driving forces like easy access of learning material, lecture notes and exposure to important questions, which may be useful in the final examination. However, most of the students found it difficult to access e-learning outside the campus, which was identified a major restraining force by the study group. Moreover, the study group affirmed that the e-learning portal was not user friendly enough to facilitate optimum utilization. On computation of the total scores, the restraining forces had a total score of 14 while the driving forces added up to a total score of 12. Among the driving forces, the utility of e-learning in learning important topics was given a score of 3 out of 5 . Difficulty in access of e-learning outside the campus was highlighted by the group as a major restraining force, with a score of 4 out of 5 (Figure 2). Therefore, this indicates a need to take corrective action by strengthening the driving forces or overcoming the restrictive forces. In this regard, the study group suggested changes to alter the factors influencing e-learning use and thereby improve the quality and use of e-learning activities. They recommended that e-learning should be made easily accessible outside the campus, to encourage maximum participation. Steps needed to be taken to make e-learning user friendly. To address this issue, the study group suggested periodic orientation classes for students regarding the use of e-learning. In order to break the monotony and arouse interest, video demonstrations, images, illustrations and clinical scenario based questions should be uploaded, rather than lecture notes or materials. Moreover, they also suggested that e-learning may be used a platform to sensitize the students regarding the Indian Postgradu- ate Medical Entrance Examinations, by incorporating Multiple Choice Questions. Furthermore, downloadable e-books may be uploaded to the e-learning portal.

Thus, the findings of this study showed that majority of the study participants found e-learning to be useful overall. However, factors like inaccessibility of e-learning outside the campus and lack of user friendliness may be detrimental to the use of e-learning among medical undergraduate students.

Table 1: Pattern of computer and internet usage among study participants

\begin{tabular}{|c|c|c|}
\hline Variables & $\begin{array}{c}\text { Total } \\
\text { number } \\
\text { of study } \\
\text { participants } \\
(n=323)\end{array}$ & Percentage (\%) \\
\hline \multicolumn{3}{|l|}{ Own computer/laptop } \\
\hline Yes & 320 & $99.03 \%$ \\
\hline $\begin{array}{c}\text { No } \\
\text { Access to internet }\end{array}$ & 3 & $0.93 \%$ \\
\hline Yes & 319 & $98.76 \%$ \\
\hline Duration of internet use per day & 4 & $1.24 \%$ \\
\hline Several times in a day & 206 & $63.77 \%$ \\
\hline Once a day & 56 & $17.34 \%$ \\
\hline Few times a week & 44 & $13.62 \%$ \\
\hline Few times a month & 10 & $3.09 \%$ \\
\hline $\begin{array}{l}\text { Rarely } \\
\text { Hours spent online on academic } \\
\text { activities }\end{array}$ & 7 & $2.18 \%$ \\
\hline$<1$ hour & 216 & $66.87 \%$ \\
\hline 1-2 hours & 70 & $21.67 \%$ \\
\hline 2-4 hours & 31 & $9.60 \%$ \\
\hline $\begin{array}{c}>4 \text { hours } \\
\text { Hours spent online on leisure } \\
\text { activities }\end{array}$ & 6 & $1.86 \%$ \\
\hline$<1$ hour & 122 & $37.77 \%$ \\
\hline 1-2 hours & 78 & $24.15 \%$ \\
\hline 2-4 hours & 73 & $22.60 \%$ \\
\hline$>4$ hours & 50 & $15.48 \%$ \\
\hline
\end{tabular}

Table 2: Self-perceived computer skills among the study participants

\begin{tabular}{ccc}
\hline Variables & $\begin{array}{c}\text { Total number of } \\
\text { study participants } \\
(\mathbf{n}=323)\end{array}$ & Percentage (\%) \\
\hline $\begin{array}{c}\text { Overall skills in using } \\
\text { computers }\end{array}$ & 266 & $82.35 \%$ \\
Yes & 57 & $17.65 \%$ \\
No & & \\
Good keyboard skills & 253 & $78.33 \%$ \\
Yes & 70 & $21.67 \%$ \\
No & & \\
Confidence in using Microsoft & & \\
Word & 246 & $76.16 \%$ \\
Yes & 77 & $23.84 \%$ \\
No & & $78.64 \%$ \\
Confidence in using & 254 & $21.67 \%$ \\
PowerPoint & 69 & \\
Yes & & \\
No & &
\end{tabular}


Table 3: Pattern of utilization and self-proficiency regarding e-learning use among the study participants

\begin{tabular}{ccc}
\hline Variables & $\begin{array}{c}\text { Total number of study } \\
\text { participants } \\
(\mathbf{n}=323)\end{array}$ & $\begin{array}{c}\text { Percentage } \\
(\%)\end{array}$ \\
\hline Access e-learning & 266 & $82.35 \%$ \\
Yes & 57 & $17.65 \%$ \\
No & & \\
Frequency of e-learning & 31 & $9.59 \%$ \\
access & 57 & $17.65 \%$ \\
Several times a day & 113 & $34.98 \%$ \\
Once a day & 57 & $17.65 \%$ \\
Few times a week & 65 & $20.13 \%$ \\
Few times a month & & \\
Rarely & & $59.75 \%$ \\
Proficient in usage of & 264 & $40.25 \%$ \\
e-learning & 59 & \\
Yes & &
\end{tabular}

Table 4: Perceived usefulness of different e-learning resources as a teaching, learning and assessment method among the study participants

\begin{tabular}{|c|c|c|}
\hline Variables & $\begin{array}{c}\text { Total number of } \\
\text { study participants } \\
(\mathrm{n}=323)\end{array}$ & $\begin{array}{c}\text { Percentage } \\
\text { (\%) }\end{array}$ \\
\hline \multicolumn{3}{|l|}{ Descriptive texts/PowerPoint } \\
\hline Useful & 219 & $67.80 \%$ \\
\hline Not useful & 104 & $32.20 \%$ \\
\hline \multicolumn{3}{|l|}{ Images } \\
\hline Useful & 268 & $82.97 \%$ \\
\hline Not useful & 55 & $17.03 \%$ \\
\hline \multicolumn{3}{|l|}{ Video demonstrations } \\
\hline Useful & 248 & $76.78 \%$ \\
\hline Not useful & 75 & $23.22 \%$ \\
\hline \multicolumn{3}{|l|}{ Forum discussions } \\
\hline Useful & 211 & $65.32 \%$ \\
\hline Not useful & 112 & $34.68 \%$ \\
\hline \multicolumn{3}{|l|}{ Online quiz } \\
\hline Useful & 234 & $72.45 \%$ \\
\hline Not useful & 89 & $27.55 \%$ \\
\hline \multicolumn{3}{|l|}{$\begin{array}{l}\text { Preferred type of e-learning } \\
\text { resource }\end{array}$} \\
\hline Descriptive texts/PowerPoint & 64 & $19.81 \%$ \\
\hline Images/video demonstrations & 102 & $31.58 \%$ \\
\hline Forum activities & 72 & $22.29 \%$ \\
\hline Online quiz/assessments & 85 & $26.31 \%$ \\
\hline
\end{tabular}

\section{DISCUSSION}

The results of our study suggest that the undergraduate medical students value the use of e-learning. However, they vary in their approach as well as utilization of such learning resources.

Nearly all the study participants owned a computer and had access to internet through a broadband network. On the contrary, a study conducted by Link et al, in Vienna, Austria reported that a sizeable number of students had internet access only via dial-up connections, using a modem. ${ }^{10}$ In order to make best use of e-learning, one must possess
Table 5: Attitudes of the study participants towards e-learning

\begin{tabular}{|c|c|c|}
\hline E-learning & $\begin{array}{c}\text { Total number of } \\
\text { study participants } \\
(n=323)\end{array}$ & Percentage (\%) \\
\hline \multicolumn{3}{|l|}{ Useful overall } \\
\hline Yes & 201 & $62.29 \%$ \\
\hline No & 122 & $31.71 \%$ \\
\hline \multicolumn{3}{|l|}{ User friendly } \\
\hline Yes & 193 & $59.75 \%$ \\
\hline No & 130 & $40.25 \%$ \\
\hline \multicolumn{3}{|c|}{ Useful to prepare for exams } \\
\hline Yes & 184 & $56.96 \%$ \\
\hline No & 139 & $43.03 \%$ \\
\hline \multicolumn{3}{|c|}{ Improves teaching standard } \\
\hline Yes & 170 & $52.63 \%$ \\
\hline No & 153 & $47.46 \%$ \\
\hline \multicolumn{3}{|c|}{ Encourages to read books } \\
\hline Yes & 112 & $34.67 \%$ \\
\hline No & 211 & $65.33 \%$ \\
\hline \multicolumn{3}{|c|}{$\begin{array}{c}\text { Good as traditional } \\
\text { teaching }\end{array}$} \\
\hline Yes & 111 & $34.36 \%$ \\
\hline \multicolumn{3}{|l|}{$\begin{array}{c}\text { No } \\
\text { Improves exam } \\
\text { performance }\end{array}$} \\
\hline Yes & 144 & $44.58 \%$ \\
\hline No & 179 & $55.42 \%$ \\
\hline
\end{tabular}

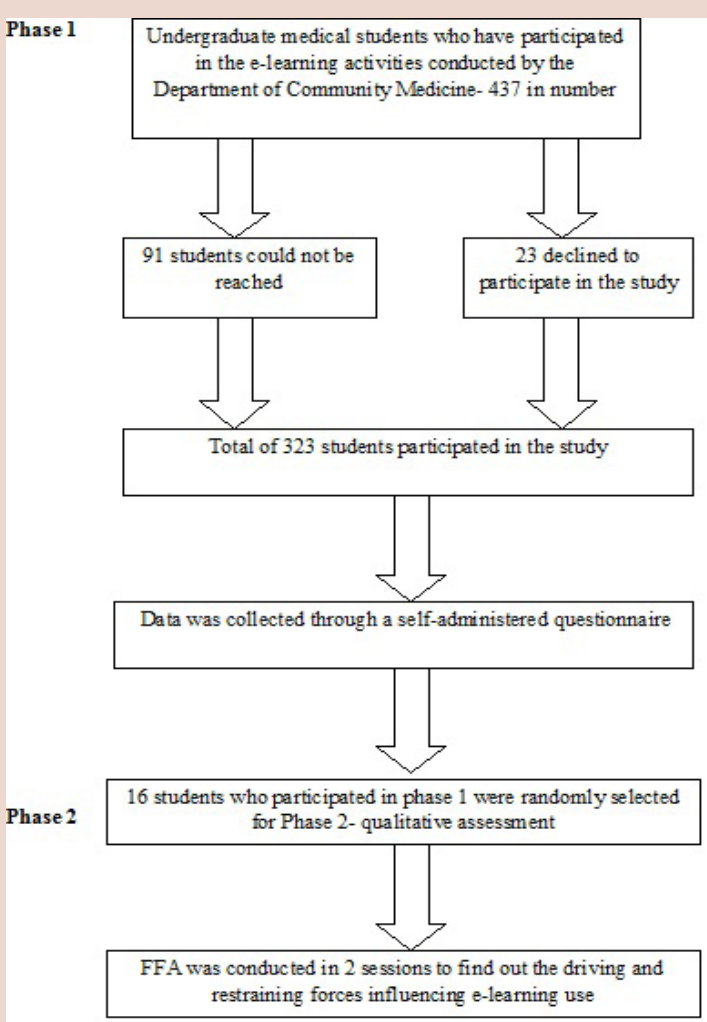

Figure 1: An outline of the approach adopted in this study 
DRIVING FORCES

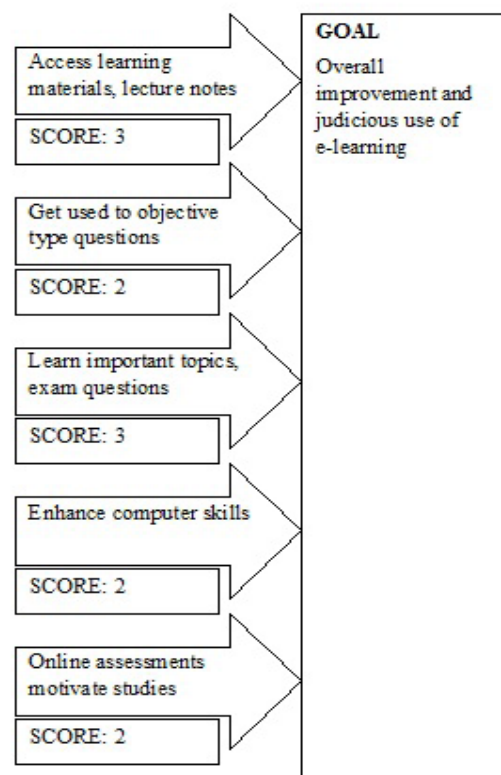

Total Score For: 12
RESTRAINING FORCE S

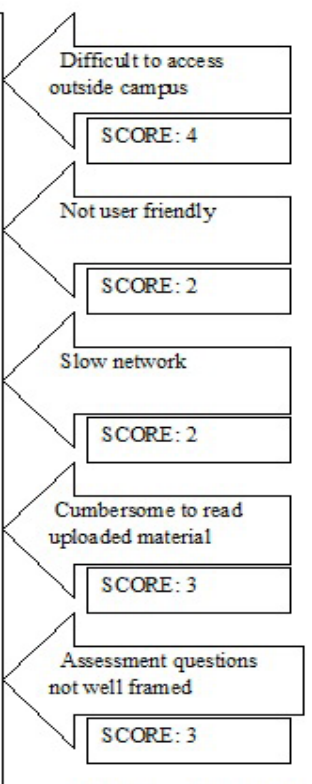

Total Score Against: 14
Figure 2: Force field analysis of factors influencing e-learning use

adequate computer knowledge and skills. In addition, confidence to operate the computers smoothly is imperative to facilitate utilization of the e-learning resources to the maximum. Majority of the study participants were self-confident in using computers. This was comparable with the findings of a study conducted on final year Indian medical students in, the findings of which indicated that medical students displayed a good knowledge regarding the use of computers and internet. This study by Chudasama et al, showed that medical students have access to substantial information technology resources and demonstrated knowledge towards computer and internet. ${ }^{4}$

We found out through the present study, that a wide majority of the students accessed the e-learning portal. This was in agreement with the findings of a study by Yappa et al, who reported that $65.7 \%$ participated in e-learning activities. ${ }^{11}$ As far as the preferred type of

e-learning activity was concerned, most agreed that video demonstrations, illustrations and images should be uploaded to arouse interest among the students. In comparison, a study by Gormley et al, reported that demonstration videos, images will be useful in the learning of clinical skills. ${ }^{5}$

Most of the students disagreed that e-learning is as good as traditional teaching. This finding was in concordance with a study conducted at the Medical University of Vienna. However, the findings of that study also concluded that e-learning could serve as a supplement for lectures and seminars. ${ }^{7}$ In a Danish context, Dorup reported that a slightly greater number of students were in favour of replacing traditional lectures with e-learning. This could be explained by the fact that different response scales were used for assessment. ${ }^{12}$

Difficulty to access e-learning outside the Medical College campus, lack of user friendliness, uninteresting questions posed by the teachers and difficulty in grasping the study material were identified as barriers to effective use of e-learning. A study carried out by Link, who conducted a focused group discussion on faculty and students, reported that students had serious doubts about the usability and efficiency of e-learning. ${ }^{10}$

We were able to find out certain driving and restraining forces which may influence learning, on the basis of FFA, which helps to look at all forces for and against a plan and weigh the significance of these factors individually. There have been very few instances of FFA being used as a research tool in medical education. Cathro, in her study to find out the driving and restraining forces in pursuing graduate studies in nursing education, successfully applied the technique of FFA. The findings implied that nurses may be interested in graduate studies, if the driving forces outweigh the restraining forces. ${ }^{13}$

Our study concludes that most of the study participants believed that e-learning is helpful. They had access to substantial information technology resources and demonstrated good confidence towards usage of computer and internet. However, in spite of the benefits that will emanate as a result of implementation of e-learning, there persist various challenges, which need to be brought to the immediate attention of the authorities. Several issues act as barriers to better utilization of e-learning among students. Formal orientation programmes for students are the need of the hour. Provision of structured computer and information technology training for medical students would equip them with the skills they need to utilize e-learning in a more desirable manner. To enhance the judicious use of e-learning, training for faculty is a must. Moreover, e-learning may be used as a platform to sensitize medical students about the basics of clinical examination and certain important medical procedures by uploading relevant videos, images and illustrations. A judicious use of e-learning may certainly act as a supplement to the conventional classroom teaching. Despite e-learning being an evolving approach in medical education, careful consideration needs to be given to the usability, utility as well as sustainability of the same, which may lead to successful implementation of such an approach, thereby smoothening the process of teaching and learning.

However, the results of our study should be interpreted with caution as it suffers from a limitation. The cross-sectional nature of our study limits the assessment of the effectiveness of e-learning among the undergraduate medical students. The relationship between e-learning use and academic performance could not be determined.

\section{ACKNOWLEDGEMENTS}

We express our heartfelt gratitude to all the participants of this research who shared their valuable experiences and spent their precious time.

Source(s) of support:

There was no source of support or funding for this study.

\section{CONFLICT OF INTEREST}

We hereby declare that there was no conflict of interest involved in the publication of this study.

\section{ABBREVIATION USED}

FFA: Force Field Analysis; MBBS: Bachelor of Medicine and Bachelor of Surgery.

\section{REFERENCES}

1. Williams B, Boyle M, Molloy A, Brightwell R, Munro G, Service M. Undergraduate paramedic students attitudes to e-learning findings from five university programmes. Research in Learning Technology. 2011;19(2):89-100.

2. Brown $T$, Zoghi M, Williams M, Jaberzadeh $S$, Roller L, Palermo C. Are learning style preferences of health science students predictive of their at titudes towards e-learning?. Australasian Journal of Educational Technology. 2009;25(4):524-43 
3. Ruiz JG, Mintzer MJ, Leipzig RM. The Impact of E-Learning in Medical Education. Academic Medicine. 2006;81(3):208-12

4. Chudasama R, Godara N, Srivastava R. Assessing computer literacy and attitude towards e-learning among final year medical students. The Internet Journal of Medical Informatics [Internet] 2008 [cited 2015 October 8]; 5(1). Available from: https://ispub.com/lJMI/5/1/11322

5. Mehra V, Omidian F. Examining Students' Attitudes Towards E-learning: A Case from India. Malaysian Journal of Medical Education Technology. 2011;11(2):13-8.

6. Gromley GJ, Collins K, Boohan M, Bickle IC, Stevenson M. Is there a place for e-learning in clinical skills? A survey of undergraduate medical students' experiences and attitudes. Medical Teacher. 2009;31:e6-e12.

7. Malterud K. The art and science of clinical knowledge: evidence beyond measures and numbers. Lancet. 2001;358:397-400.

8. Bozak MG. Using Lewin's force field analysis in implementing a nursing information system. Comput Inform Nurs. 2003;21(2):80-5
9. Kaminski J. Theory applied to informatics-Lewin's Change Theory. Canadian Journal of Nursing Informatics 2011 [cited 2015 September 10]; 6(1). Available from: http://cjni.net/journal/?p=1251

10. Link TM, Marz R. Computer literacy and attitudes towards e-learning among first year medical students. BMC Medical Education. 2006;6:34.

11. Yappa YMMM, Dilan MMNS, Karunaratne WCD, Widisinghe CC, Hewapathirana R, Karunathilake I. Computer literacy and attitudes towards e-learning among Srilankan Medical Students. Srilanka Journal of Bio-Medical Informatics. 2012;3(3):82-96

12. Dørup J. Experience and attitudes towards information technology among firstyear medical students in Denmark: Longitudinal questionnaire survey. J Med Internet Res. 2004;6:e10.

13. Cathro H. Pursuing Graduate Studies in Nursing Education: Driving and Restraining Forces. The Online Journal of Issues in Nursing [Internet] 2011 [cited 2015 October 9]; 16(3). Available from: http://www.nursingworld.org/MainMenuCategories/ANAMarketplace/ANAPeriodicals/OJIN/TableofContents/Nol-162011/No3-Sept-2011.aspx

Cite this article : Raghuveer P, Nirgude AS. Sarkar S. Utility Of E-learning in Community Medicine: A Mixed Methods Assessment Among Indian Medical Students. Int. J. Med. Public Health, 2016; 6(2):88-93. 